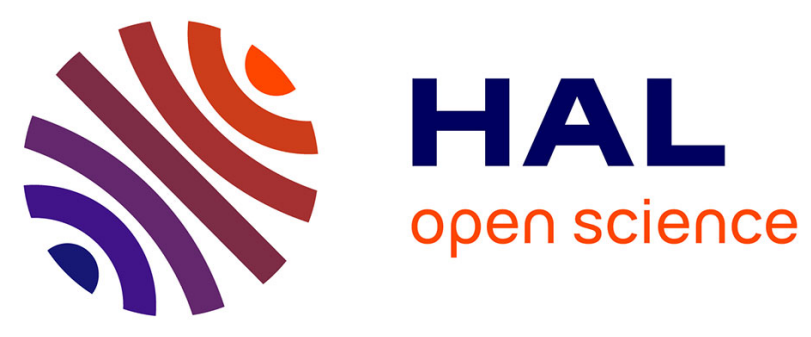

\title{
Responsible Design, Implementation and Use of Information and Communication Technology
}

Marié Hattingh, Machdel Matthee, Hanlie Smuts, Ilias Pappas, Yogesh K. Dwivedi, Matti Mäntymäki

\section{- To cite this version:}

Marié Hattingh, Machdel Matthee, Hanlie Smuts, Ilias Pappas, Yogesh K. Dwivedi, et al.. Responsible Design, Implementation and Use of Information and Communication Technology: 19th IFIP WG 6.11 Conference on e-Business, e-Services, and e-Society, I3E 2020, Skukuza, South Africa, April 6-8, 2020, Proceedings, Part I. Springer International Publishing, LNCS-12066, 2020, Lecture Notes in Computer Science, 978-3-030-44998-8. 10.1007/978-3-030-44999-5 . hal-03222812

\section{HAL Id: hal-03222812 \\ https://hal.inria.fr/hal-03222812}

Submitted on 10 May 2021

HAL is a multi-disciplinary open access archive for the deposit and dissemination of scientific research documents, whether they are published or not. The documents may come from teaching and research institutions in France or abroad, or from public or private research centers.
L'archive ouverte pluridisciplinaire HAL, est destinée au dépôt et à la diffusion de documents scientifiques de niveau recherche, publiés ou non, émanant des établissements d'enseignement et de recherche français ou étrangers, des laboratoires publics ou privés.

\section{(c)(1)}

Distributed under a Creative Commons Attribution| 4.0 International License 


\section{Lecture Notes in Computer Science}

Founding Editors

Gerhard Goos

Karlsruhe Institute of Technology, Karlsruhe, Germany

Juris Hartmanis

Cornell University, Ithaca, NY, USA

Editorial Board Members

Elisa Bertino

Purdue University, West Lafayette, IN, USA

Wen Gao

Peking University, Beijing, China

Bernhard Steffen (1)

TU Dortmund University, Dortmund, Germany

Gerhard Woeginger (1)

RWTH Aachen, Aachen, Germany

Moti Yung

Columbia University, New York, NY, USA 
More information about this series at http://www.springer.com/series/7409 
Marié Hattingh · Machdel Matthee .

Hanlie Smuts · Ilias Pappas .

Yogesh K. Dwivedi · Matti Mäntymäki (Eds.)

\section{Responsible Design,}

Implementation and Use

of Information and

Communication Technology

19th IFIP WG 6.11 Conference on

e-Business, e-Services, and e-Society, I3E 2020

Skukuza, South Africa, April 6-8, 2020

Proceedings, Part I

黛 Springer 


\section{Editors}

Marié Hattingh

University of Pretoria

Pretoria, South Africa

Hanlie Smuts

University of Pretoria

Pretoria, South Africa

Yogesh K. Dwivedi (D)

Swansea University

Swansea, UK

\author{
Machdel Matthee \\ University of Pretoria \\ Pretoria, South Africa \\ Ilias Pappas (iD \\ University of Agder \\ Kristiansand, Norway \\ Matti Mäntymäki \\ University of Turku \\ Turku, Finland
}

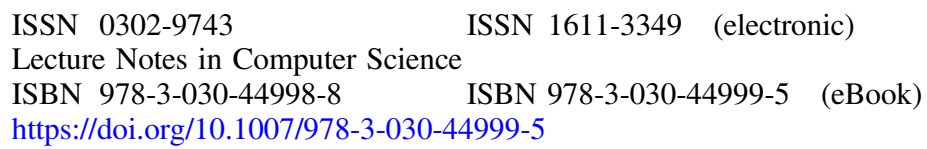

LNCS Sublibrary: SL3 - Information Systems and Applications, incl. Internet/Web, and HCI

(c) IFIP International Federation for Information Processing 2020

This work is subject to copyright. All rights are reserved by the Publisher, whether the whole or part of the material is concerned, specifically the rights of translation, reprinting, reuse of illustrations, recitation, broadcasting, reproduction on microfilms or in any other physical way, and transmission or information storage and retrieval, electronic adaptation, computer software, or by similar or dissimilar methodology now known or hereafter developed.

The use of general descriptive names, registered names, trademarks, service marks, etc. in this publication does not imply, even in the absence of a specific statement, that such names are exempt from the relevant protective laws and regulations and therefore free for general use.

The publisher, the authors and the editors are safe to assume that the advice and information in this book are believed to be true and accurate at the date of publication. Neither the publisher nor the authors or the editors give a warranty, expressed or implied, with respect to the material contained herein or for any errors or omissions that may have been made. The publisher remains neutral with regard to jurisdictional claims in published maps and institutional affiliations.

This Springer imprint is published by the registered company Springer Nature Switzerland AG The registered company address is: Gewerbestrasse 11, 6330 Cham, Switzerland 


\section{Preface}

This book presents the proceedings of the 19th International Federation of Information Processing (IFIP) Conference on e-Business, e-Services, and e-Society (I3E 2020), which was held in Skukuza, Kruger National Park, South Africa, during April 6-8, 2020. The annual I3E conference is a core part of Working Group 6.11, which aims to organize and promote the exchange of information and co-operation related to all aspects of e-Business, e-Services, and e-Society (the three Es). The I3E conference series is truly interdisciplinary and welcomed contributions from both academics and practitioners alike.

The main theme of the 2020 conference was "Responsible design, implementation and use of information and communication technology." In line with the inclusive nature of the I3E series, all papers related to e-Business, e-Services, and e-Society were welcomed.

The age of digital transformation opens up exciting new avenues for design and application of ICTs. Yet, with the ubiquitous connectedness of a digitally transformed world, come unintended, unpredictable, and often adverse consequences for individuals, societies, and organizations - in developed and developing contexts. Security, privacy, trustworthiness, exploitation, and well-being are some of the pressing concerns resulting from new digital realities.

There is need for responsible design, implementation, and use of information systems (IS) based on critical awareness and ethical practices. As rightly put by Schultze (2017:65): “As IS researchers we need to examine our own practices - including the questions we ask, the methods we deploy and theories we adopt - to understand and critically review our world-making."

The IFIP I3E 2020 was held during April 6-8, 2020, and brought together contributions from a variety of perspectives, disciplines, and communities for the advancement of knowledge regarding responsible design, implementation, and use of information and communications technology. This was evident by our variety of keynote speakers and topics for the panel discussions. We were delighted to welcome three distinguished keynote speakers:

- Mr. James van der Westhuizen who is the founder and managing partner of KnowHouse, founded 20 years ago out of a passion to work differently with the challenge of learning and change in organizations. He is a global consultant and facilitator working across the African continent, the Middle East, Europe, and Asia.

- Prof. Irwin Brown is a full Professor and Head of the Department of Information Systems (IS) at the University of Cape Town. His research interests relate to theorizing about IS phenomena in developing countries.

- Prof. Dr. Shirish C. Srivastava is a tenured full Professor and holds the GS1 Chair on 'Digital Content for Omni Channel' at HEC Paris. His rich experience includes coaching senior executives on issues related to managing technology emerging technologies (such as big data, blockchains, and artificial intelligence), technology 
enabled innovation, entrepreneurship, and managing cross-border business relationships.

The conference held two panels to facilitate discussions on important topics. The first panel on "Blockchain - hope or hype? Blockchain as a disruptive force" was chaired by Dr. Matti Mäntymäki. Blockchain is surrounded by considerable optimism and enthusiasm among businesses and academia. This enthusiasm is evidenced by the numerous calls for papers in journals and dedicated blockchain tracks in conferences. The purpose of the panel was to make sense of the actual significance of the blockchain phenomenon and provoke discussion and exchange of ideas among the I3E community. To this end, the panel paid homage to the heterogenous nature of the I3E community and invited a diverse of group of expert panellists to share their distinctive perspectives on blockchain.

The second panel, made up of a panel of editors, was chaired by Dr. Shirish C. Srivastava. The panel consisted of six journal editors from international and local (South African) publications. Each editor gave an explanation on the requirements for authors when submitting to their journal.

The Call for Papers solicited submissions in two main categories: full research papers and short research-in-progress papers. Each submission was reviewed by at least two knowledgeable academics in the field, in a double-blind process. The 2020 conference received 191 submissions. Out of the 191 papers, 91 papers were selected to be presented at the conference. Four of the accepted papers were not included in the final proceedings because the authors decided to withdraw it. Thus, the acceptance rate was $45.5 \%$.

Following the conference, two special issues were organized for selected best papers of the I3E 2020. The two special issues are in the International Journal of Information Management (IJIM) and the International Journal of Electronic Government Research (IJEGR).

The final set of 87 full and short papers submitted to I3E 2020 that appear in these proceedings were clustered into 14 groups, each of which are outlined below.

Part I: addressing the area of Blockchain. Three papers were grouped under this theme. One of the papers proposed a framework for the adoption of blockchain whilst another reported on the application of blockchain technology in Healthcare. The third paper examined the potential disruptive impact of cryptocurrencies.

Part II of the book addressed papers on the Fourth Industrial Revolution. Nine papers were grouped under this theme. Paper details range from a systematic literature review on the incompatibility of Smart manufacturing for SMMEs to the development of models and frameworks through the application of Smart technologies. One paper included a bibliographic coupling and co-occurrence on the topic of Smart City and Economy, whilst another reported on robotic automation and the consequences for knowledge workers. The final paper reported on the co-creation for digitalization in Norwegian business clusters.

Part III of the book addressed e-Business. 12 papers were grouped under this theme. The papers presented works on online banking quality, a conceptual framework for digital entrepreneurship, mobile applications, online switching behavior, and how games are used in business. Three papers reported on systematic review of literature on 
eWOM, mobile shopping acceptance predictors and social commerce adoption predictors. The final paper presented a review of papers published from 2001 to 2019 by I3E.

Part IV of the book addressed Business Processes. 10 papers were grouped under this theme. The papers presented works on governance achieved through business process management, how IT is being used in Fintech Innovation, a meta model for maturity models, and a strategic model for the safeguarding the preservation of business value. In addition to these themes, papers were presented on using the story-card method for business process re-engineering, using Zachman's framework as an IS theory and a review of the Task-Technology Fit Theory.

Part V of the book addressed Big Data and Machine Learning. Seven papers were grouped under this theme. The papers presented work on using machine learning in the field of healthcare, data governance, using a deep learning neural network model to predict information diffusion on Twitter, and big data visualization tools.

Part VI of the book addresses ICT and Education. Seven papers were grouped under this theme. The papers presented work on mobile learning, new considerations for flipped classroom approach, and eModeration system considerations.

Part VII of the book addressed eGovernment. Six papers were grouped under this theme. The papers presented work on the use of social media in eParticipation, enterprise architectures in eGovernments, and eGovernment implementation framework. Other themes included were digital innovation in public organizations, implementation challenges in eProcurement, and a case from Ghana on the effects on National Health Insurance digital platform development and use.

Part VIII of the book addressed eHealth. Six papers were grouped under this theme. Papers presented work on the use of technology for diabetic patients, factors influencing community health workers, wearable devices, and a Twitter social network analysis of the South African Health Insurance Bill.

Part IX of the book addressed Security. Four papers were grouped under this theme. Papers presented work on cyber-harassment among LGBTQIA+ youth, online identity theft, cybersecurity readiness of e-tail organizations, and the ethics of using publicly available data.

Part X of the book addressed Social Media. Six papers were grouped under this theme. Papers presented works on a conceptual framework for media use behavior, metaphors of social media, credibility of online information (fake news), and problematic media and technology use.

Part XI of the book addressed Knowledge and Knowledge Management. Three papers were grouped under this theme. Papers presented work on knowledge transfer science education, a knowledge asset management implementation framework, and a conceptual knowledge visualization framework for knowledge transfer.

Part XII of the book addressed ICT for Gender Equality and Development. Nine papers were grouped under this theme. Papers presented work on the rural vs urban digital divide, socio-economic factors in Internet usage in Nigeria, and enablers and barriers of mobile commerce and banking services among elderly individuals. A methodology for addressing the second-level digital divide, gender equality in the ICT context, digital competence requirements, and the influence of culture on women's IT career choices were also presented. 
Part XIII of the book addressed Information Systems for Governance. Four papers were grouped under this theme. Papers presented work on the use of machine learning on financial inclusion data for governance in Eswatini, ordinance-tweet mining to disseminate urban policy knowledge for smart governance, open technology innovation in healthcare services, and multi-stakeholder-centric data analytics governance framework.

Part XIV of the book addressed User Experience and Usability. Three papers were grouped under this theme. Papers presented work on the use of machine learning and eye tracking to predict users' ratings on the aesthetics of websites, a systematic review on designing for positive emotional responses in users of interactive digital technologies, and a methodology to compare the usability of information systems.

The success of the 19th IFIP I3E Conference (I3E 2020) was a result of the enormous efforts of numerous people and organizations. Firstly, this conference was only made possible by the continued support of WG 6.11 for this conference series and for selecting South Africa to host it in 2020, for which we are extremely grateful. We received many good-quality submissions from authors across the globe and we would like to thank them for choosing I3E 2020 as the outlet to present and publish their current research. We are indebted to the Program Committee, who generously gave up their time to provide constructive reviews and facilitate the improvement of the submitted manuscripts. We would like to thank the Department of Informatics of the University of Pretoria for their support in enabling us to host this conference. Thank you to AfricaMassive that assisted us with all the logistical arrangements with hosting the conference in Skukuza located in the Kruger National Park. Finally, we extend our sincere gratitude to everyone involved in organizing the conference, to our esteemed keynote speakers, and to Springer LNCS as the publisher of these proceedings, which we hope will be of use for the continued development of research related to the three $\mathrm{Es}^{1}$.

February 2020

\author{
Marié Hattingh \\ Machdel Matthee \\ Hanlie Smuts \\ Ilias Pappas \\ Yogesh K. Dwivedi \\ Matti Mäntymäki
}

\footnotetext{
${ }^{1}$ Due to the global COVID-19 pandemic and the consequential worldwide imposed travel restrictions and lock down, the I3E 2020 conference event scheduled to take place in Skukuza, South Africa, was unfortunately cancelled.
} 


\section{Organization}

\section{Conference Chairs}

\author{
Marié (M. J.) Hattingh \\ Machdel Matthee \\ Hanlie Smuts \\ Ilias Pappas
}

Yogesh K. Dwivedi

Matti Mäntymäki
University of Pretoria, South Africa

University of Pretoria, South Africa

University of Pretoria, South Africa

University of Adger and Norwegian University

of Science and Technology (NTNU), Norway

Swansea University, UK

University of Turku, Finland

\section{Program Committee Chairs}

Marié (M. J.) Hattingh

Machdel Matthee

Hanlie Smuts

Ilias Pappas

Yogesh K. Dwivedi

Matti Mäntymäki

\section{Keynote Speakers}

Irwin Brown

James van der Westhuizen

Shirish C. Srivastava

\section{Program Committee}

\author{
Rami Abu Wadi \\ Funmi Adebesin \\ Kayode Ibrahim Adenuga \\ Michael Adu Kwarteng \\ Augustus Barnnet Anderson \\ Bokolo Anthony Jnr. \\ Oluwasefunmi Arogundade \\ Lynette Barnard \\ Clara Benac Earle \\ Khalid Benali \\ Djamal Benslimane \\ Edward Bernroider
}

University of Pretoria, South Africa

University of Pretoria, South Africa

University of Pretoria, South Africa

University of Adger and Norwegian University

of Science and Technology, Norway

Swansea University, UK

University of Turku, Finland

University of Cape Town, South Africa

KnowHouse, South Africa

HEC Paris, France

\author{
Ahlia University, Bahrain \\ University of Pretoria, South Africa \\ Universiti Tecknologi, Malaysia \\ Tomas Bata University, Czech Republic \\ University of Ghana, Ghana \\ Norwegian University of Science and Technology, \\ Norway \\ Chinese Academy of Science, China \\ Nelson Mandela University, South Africa \\ Polytechnic University of Madrid, Spain \\ University of Lorraine, France \\ Claude Bernard University Lyon 1, France \\ Vienna University of Economic and Business, Austria
}


Elmi Bester

Dzifa Bibi

Katja Bley

Deonie Botha

Jacques Brosens

Paul Brous

Peter André Busch

Andre Calitz

Sunil Choenni

Mahdieh Darvish

Dinara Davlembayeva

Carina De Villiers

Marne de Vries

Jules Degila

Denis Dennehy

Vipin Deval

Christos Douligeris

Dirk Draheim

Alena Droit

Jacobus Du Preez

Edward Entee

Sunet Eybers

Olakumbi Fadiran

Sam February

Jennifer Ferreira

Blanka Frydrychova

Klimova

Shang Gao

Ping Gao

Aurona Gerber

Claude Godart

Javier Gomez

Anastasia Griva

Sara Grobbelaar

Lucas Gumbi

Hong Guo

Remko Helms

Raoul Hentschel

Grant Royd Howard

Vigneswara Ilavarasan

Marijn Janssen

Debora Jeske

Arpan Kar

Caroline Khene

Eija Koskivaara
UNISA, South Africa

University of Ghana, Ghana

Dresden University of Technology, Germany

Deloitte, South Africa

University of Pretoria, South Africa

Delft University of Technology, The Netherlands

University of Agder, Norway

Nelson Mandela University, South Africa

Research and Documentation Centre (WODC), Ministry of Justice, The Netherlands

ESCP Business School, Germany

Newcastle University, UK

University of Pretoria, South Africa

University of Pretoria, South Africa

Institute of Mathematics and Physics, Benin

National University of Ireland, Ireland

Tallinn University of Technology, Estonia

University of Piraeus, Greece

Software Competence Center Hagenberg, Austria

Osnabrueck University, Germany

University of Pretoria, South Africa

University of Ghana, Ghana

University of Pretoria, South Africa

UNISA, South Africa

Accenture, South Africa

Victoria University of Wellington, New Zealand

University of Hradec Kralove, Czech Republic

Örebro University, Sweden

The University of Manchester, UK

University of Pretoria, South Africa

University of Lorraine, France

Autonomous University of Madrid, Spain

Athens University of Economics and Business, Greece

Stellenbosch University, South Africa

UNISA, South Africa

Anhui University, China

The Open University, The Netherlands

Dresden University of Technology, Germany

UNISA, South Africa

Indian Institute of Technology, India

Delft University of Technology, The Netherlands

University College Cork, Ireland

Indian Institute of Technology, India

Rhodes University, South Africa

University of Turku, Finland 


\author{
Paula Kotzé \\ Jan H. Kroeze \\ Rendani Kruger \\ Abhinav Kumar \\ Amit Kumar \\ Andreas D. Landmark \\ Sven Laumer \\ Daniel Le Roux \\ Hongxiu Li \\ Lieb Liebenberg \\ Marianne Loock \\ Hugo Lotriet \\ Mario Marais \\ Emanuele Gabriel \\ Margherita \\ Davit Marikyan \\ Linda Marshall \\ Tendani Mawela \\ Nita Mennega \\ Jan Mentz \\ Patrick Mikalef
}

Tshepiso Mokoena

Mathias Mujinga

Matthias Murawski

Mohammed Khaled

Mustafa

Mpho Mzingelwa

Rennie Naidoo

Alex Norta

Kayode Odusanya

Kwame Simpe Ofori

Kingsley Ofosu-Ampong

Olabode Ogunbodede

Leif Erik Opland

Makoto Oya

Niki Panteli

Savvas Papagiannidis

Zacharoula Papamitsiou

Sofia Papavlasopoulou
University of Pretoria, South Africa

UNISA, South Africa

University of Pretoria, South Africa

The National Institute of Technology Patna, India

Kushwaha GAP, India

SINTEF, Norway

Friedrich-Alexander-Universität Erlangen-Nürnberg, Germany

Stellenbosch University, South Africa

Turku School of Economics, Finland

University of Pretoria, South Africa

UNISA, South Africa

UNISA, South Africa

CSIR Meraka Institute, South Africa

Tuscia University, Italy

Newcastle University, UK

University of Pretoria, South Africa

University of Pretoria, South Africa

University of Pretoria, South Africa

UNISA, South Africa

Norwegian University of Science and Technology, Norway

CSIR, South Africa

UNISA, South Africa

ESCP Europe Business School, Germany

Bangladesh University of Professionals, Bangladesh

University of KwaZulu Natal, South Africa

University of Pretoria, South Africa

Tallinn University of Technology, Estonia

Loughborough University, UK

University of Electronic Science and Technology of China, China

University of Ghana, Ghana

Newcastle University, UK

Norwegian University of Science and Technology, Norway

Computer Institute of Japan, Japan

Royal Holloway University of London, UK

Newcastle University, UK

Norwegian University of Science and Technology, Norway

Norwegian University of Science and Technology, Norway 


\section{Elena Parmiggiani}

Douglas Parry

Marcel Pikhart

Colin Pilkington

Komla Pillay

Henk Pretorius

Tania Prinsloo

Maciel Queiroz

Van Raj

Nripendra Rana

Anthony Renner-Micah

Suzanne Sackstein

Brenda Scholtz

Lisa Seymour

Anuragini Shirish

Djofack Sidonie

Ivana Simonova

Konstantina Spanaki

Ruan Spies

Riana Steyn

Ilse Struweg

Zhaohao Sun

Reima Vesa Suomi

Libuse Svobodova

Kuttimani Tamilmani

Maureen Tanner

Ali Tarhini

Temitope Oluwaseyi Tokosi

Cathrine Tømte

Juan Carlos Torrado Vidal

Pieter Toussaint

Rakhi Tripathi

Valentyna Tsap

Pitso Tsibolane

Marita Turpin

Parijat Upadhyay

Jean-Paul Van Belle

Judy van Biljon

Rogier Van de Wetering

Thomas van der Merwe

Alta Van der Merwe

J. P. van Deventer
Norwegian University of Science and Technology, Norway

Stellenbosch University, South Africa

University of Hradec Kralove, Czech Republic

UNISA, South Africa

University of Pretoria, South Africa

University of Pretoria, South Africa

University of Pretoria, South Africa

Paulista University, Brazil

UNISA, South Africa

Swansea University, UK

University of Ghana, Ghana

WITS University, South Africa

Nelson Mandela University, South Africa

University of Cape Town, South Africa

University of Paris-Saclay, France

University of Yaounde II, Cameroon

University of Jan Evangelista Purkyne, Czech Republic

Loughborough University, UK

Stellenbosch University, South Africa

University of Pretoria, South Africa

University of Johannesburg, South Africa

Federation University Australia, Australia

University of Turku, Finland

University of Hradec Kralove, Czechia

Swansea University, UK

University of Cape Town, South Africa

Sultan Qaboos University, Oman

Nelson Mandela University, South Africa

University of Adger, Noway

Autonomous University of Madrid, Spain

Norwegian University of Science and Technology, Norway

FORE School of Management, India

Tallinn University of Technology, Estonia

Stellenbosch University, South Africa

University of Pretoria, South Africa

IMT Nagpur, India

University of Cape Town, South Africa

UNISA, South Africa

Open University, The Netherlands

UNISA, South Africa

University of Pretoria, South Africa

University of Pretoria, South Africa 
Corné Van Staden

Izak Van Zyl

Polyxeni Vassilakopoulou

Jari Veijalainen

Hans Weigand

Lizette Weilbach

Ted White

Michael Williams

Milla Wiren

Khulekani Yakobi

Hiroshi Yoshiura

Hans-Dieter Zimmermann
UNISA, South Africa

Cape Peninsula University of Technology, South Africa

University of Agder, Norway

University of Jyvaskyla, Finland

Tilburg University, The Netherlands

University of Pretoria, South Africa

UNISA, South Africa

Swansea University, UK

University of Turku, Finland

Nelson Mandela University, South Africa

The University of Electro-Communications, Japan

FHS St. Gallen University of Applied Sciences,

Switzerland 


\section{Contents - Part I}

\section{Block Chain}

A Framework for the Adoption of Blockchain-Based e-Procurement

Systems in the Public Sector: A Case Study of Nigeria . . . . . . . . . . . . . .

Temofe Isaac Akaba, Alex Norta, Chibuzor Udokwu, and Dirk Draheim

Blockchain Technology for Empowering Patient-Centred Healthcare:

A Pilot Study . . . . . . . . . . . . . . . . . . . . . . . . . . . .

Themba Makubalo, Brenda Scholtz, and Temitope Oluwaseyi Tokosi

Exploring the Disruptiveness of Cryptocurrencies: A Causal Layered Analysis-Based Approach. . . . . . . . . . . . . . . . . . . .

Matti Mäntymäki, Milla Wirén, and A. K. M. Najmul Islam

\section{Fourth Industrial Revolution}

SMME Readiness for Smart Manufacturing (4IR) Adoption:

A Systematic Review . . . . . . . . . . . . . . . . . . . .

Lucas Gumbi and Hossana Twinomurinzi

Using Theories to Design a Value Alignment Model for Smart City Initiatives .

Anthea van der Hoogen, Brenda Scholtz, and Andre P. Calitz.

Complementary Partnerships for SMEs: A Relational Capability Maturity

Model from an Ecosystem Perspective.

Caro Els, Sara Grobbelaar, and Denzil Kennon

The Role of Digital Connectivity in Supply Chain and Logistics Systems:

A Proposed SIMPLE Framework . . . . . . . . . . . . . . . . .

Maciel M. Queiroz and Samuel Fosso Wamba

A Strategic Organisational Perspective of Industry 4.0:

A Conceptual Model . . . . . . . . . . . . . . . . . . . . . . . . . . .

Stefan Smuts, Alta van der Merwe, and Hanlie Smuts

SMART City and Economy: Bibliographic Coupling and Co-occurrence . . . .

Libuše Svobodová and Dorota Bednarska-Olejniczak

Robotic Process Automation and Consequences for Knowledge Workers;

a Mixed-Method Study . . . . . . . . . . . . . . . . . . . . .

Tom Roar Eikebrokk and Dag Håkon Olsen 
Co-creation for Digitalization: A Study of Co-creation in Norwegian

Business Clusters . . . . . . . . . . . . . . . . . . . . . .

Dag H. Olsen, Tom Roar Eikebrokk, Kristian Aspø, and Elaine Sajets

A Framework for Industrial Internet of Things $\ldots \ldots \ldots \ldots \ldots$

Jacques Jansen and Alta van der Merwe

\section{eBusiness}

Cybersecurity Readiness of E-tail Organisations: A Technical Perspective . . . Mahmood Hussain Shah, Raza Muhammad, and Nisreen Ameen

Consumer Mobile Shopping Acceptance Predictors and Linkages:

A Systematic Review and Weight Analysis ..................

Kuttimani Tamilmani, Nripendra P. Rana, Yogesh K. Dwivedi, and Hatice Kizgin

Social Commerce Adoption Predictors: A Review and Weight Analysis. . . . . Prianka Sarker, Laurie Hughe, Yogesh K. Dwivedi, and Nripendra P. Rana

Digital Entrepreneurship in Business Enterprises: A Systematic Review . . . . . Samuel Anim-Yeboah, Richard Boateng, Emmanuel Awuni Kolog, Acheampong Owusu, and Ibrahim Bedi

Assessing the Role of Trust in Merchant Adoption of Mobile Payments

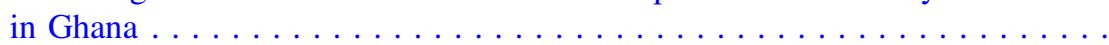

Eunice Yeboah, Richard Boateng, Acheampong Owusu, Eric Afful-Dadzie, and Joshua Ofori-Amanfo

The Influence of Price Comparison Websites on Online Switching

Behavior: A Consumer Empowerment Perspective . . . . . . . . . . . . . . . .

Michael Adu Kwarteng, Abdul Bashiru Jibril, Elsamari Botha, and Christian Nedu Osakwe

Online Banking Service Quality: A South African E-S-QUAL Analysis. . . . 228 Mathias Mujinga

The Characteristics of Digital Entrepreneurship and Digital Transformation:

A Systematic Literature Review . . . . . . . . . . . . . . . . . . Joshua Antonizzi and Hanlie Smuts

Mapping the Intellectual Progress in e-Business, e-Services and e-Society from 2001 to $2019 \ldots \ldots \ldots \ldots \ldots$. . . . . . . . . . . . . . . . . . . . . .

Zacharoula Papamitsiou and Patrick Mikalef 
Weight Analysis of the Factors Affecting eWOM Providing Behavior . . . . . .

Elvira Ismagilova, Yogesh K. Dwivedi, Nripendra P. Rana,

Uthayasankar Sivarajah, and Vishanth Weerakkody

An Intelligent Marketspace Mobile Application for Marketing

Organic Products. . . . . . . . . . . . . . . . . . . . . . . . . . . .

Oluwasefunmi 'Tale Arogundade, Adebayo Abayomi-Alli,

Kayode Adesemowo, Taiwo Bamigbade, Modupe Odusami, and Victor Olowe

How Corporates in South Africa Are Using Serious Games in Business. . . . .

Shiraz Amod and Sumarie Roodt

\section{Business Processes}

A Theoretical Framework for IT-Enabled and IT-Enforced Corporate

Governance Compliance Utilizing BPMSs .

Hendrik Willem Pretorius and Alta van der Merwe

The Role of Information Technology in Fintech Innovation:

Insights from the New York City Ecosystem . . . . . . . . . . . . . . .

Stanislav Mamonov

Governance Challenges Constraining Business Process Management:

The Case of a Large South African Financial Services Corporate . . . . . . . .

Carmen Doyle and Lisa F. Seymour

Overcoming the Ivory Tower: A Meta Model for Staged Maturity Models . . . Katja Bley, Hendrik Schön, and Susanne Strahringer

Towards a Strategic Model for Safeguarding the Preservation of Business

Value During Human Interactions with Information Systems . . . . . . . . .

Chris D. Grobler and Thomas M. van der Merwe

How to Measure Digitalization? A Critical Evaluation of Digital

Maturity Models . . . . . . . . . . . . . . . . . . . . . . . . . .

Tristan Thordsen, Matthias Murawski, and Markus Bick

Business Process Re-engineering and Agile Software Development:

Applying the Story-Card Method

Elijah Djan and Marné de Vries

The Zachman Framework for Enterprise Architecture:

An Explanatory IS Theory . . . . . . . . . . . . . . . . . . . .

Aurona Gerber, Pierre le Roux, Carike Kearney, and Alta van der Merwe 
A Scoping Review of the Application of the Task-Technology Fit Theory . . .

Ruan Spies, Sara Grobbelaar, and Adele Botha

A Broker-Based Framework for the Recommendation of Cloud Services:

A Research Proposal ...........................

Raoul Hentschel and Susanne Strahringer

\section{Big Data and Machine Learning}

Unsupervised Anomaly Detection of Healthcare Providers Using

Generative Adversarial Networks . . . . . . . . . . . . . . . . . . .

Krishnan Naidoo and Vukosi Marivate

Data Governance as Success Factor for Data Science. . . . . . . . . . . . . . .

Paul Brous, Marijn Janssen, and Rutger Krans

Happiness and Big Data - Theoretical Foundation and Empirical Insights

for Africa. . . . . . . . . . . . . . . . . . . . . . . . . . .

Anke Joubert, Matthias Murawski, Julian Bühler, and Markus Bick

Predicting Information Diffusion on Twitter a Deep Learning Neural

Network Model Using Custom Weighted Word Features . . . . . . . . . . . . . .

Amit Kumar Kushwaha, Arpan Kumar Kar,

and P. Vigneswara Ilavarasan

Requirements of Data Visualisation Tools to Analyse Big Data:

A Structured Literature Review. . . . . . . . . . . . . . . . . . .

Joy Lowe and Machdel Matthee

Implementation Considerations for Big Data Analytics (BDA):

A Benefit Dependency Network Approach . . . . . . . . . . . . . . . .

Juane Maritz, Sunet Eybers, and Marie Hattingh

A Model for Evaluating Big Data Analytics Tools

for Organisation Purposes . . . . . . . . . . . . . . . . . .

Phaphama Kangelani and Tiko Iyamu

\section{ICT and Education}

Development of a Quantitative Instrument to Measure Mobile Collaborative Learning (MCL) Using WhatsApp: The Conceptual Steps . . . . . . . . . . . . . 507 Bangisisi Zamuxolo Mathews Nyembe and Grant Royd Howard

Understanding Rural Parents' Behavioral Intention to Allow Their Children to Use Mobile Learning . . . . . . . . . . . . . . . . . . . . . . . .

David Mutambara and Anass Bayaga 
May the Change Be with You: The Need for New Roles to Support Flipped

Classroom Development

Linda Blömer, Alena Droit, and Kristin Vogelsang

Preliminary Insights into the Nature of Graduate IS Programmes

in Sub-Saharan Africa . . . . . . . . . . . . . . . . .

Mark-Oliver Kevor, Richard Boateng, Emmanuel Awuni Kolog,

Acheampong Owusu, and Anthony Afful-Dadzie

Requirements for an eModeration System in Private Schools

in South Africa.

Vanitha Rajamany, Corne J. Van Staden, and Judy van Biljon

Ready to Go? Schools' Preparedness for Teaching and Learning

Within a One-to-One Program . . . . . . . . . . . . . . . . . . .

Cathrine E. Tømte, Markus M. Bugge, Sabine Wollscheid, and Frida F. Vennerød-Diesen

Agile Development of a Flipped Classroom Course.

Linda Blömer, Christin Voigt, Alena Droit, and Uwe Hoppe 